\title{
Utilização das ferramentas da indústria 4.0 para a prototipagem no setor de vestuário
}

\author{
Use of industry 4.0 tools for prototyping in the clothing sector
}

\author{
Leide Laura Bittencourt \\ Mestranda em Design de Vestuário e Moda pela Universidade do Estado de Santa Catarina (UDESC) ) - \\ leide.maps@gmail.com-orcid.org/0000-0002-4147-315X \\ Icléia Silveira \\ Doutora em Design pela Pontifícia Universidade Católica do Rio de Janeiro (PUC-Rio)- \\ icleiasilveira@gmail.com- orcid.org/ 0000-0003-4493-9768 \\ Lucas da Rosa \\ Doutor em Design pela Pontifícia Universidade Católica do Rio de Janeiro (PUC-Rio)- \\ darosa.lucas@gmail.com-orcid.org/ 0000-0002-8429-2754 \\ Daniela Novelli \\ Doutora em Ciências Humanas pela Universidade Federal de Santa Catarina (UFSC) - \\ daniela.novelli@udesc.br-orcid.org/0000-0001-6981-8933
}

\section{Resumo}

As tecnologias digitais da Indústria 4.0, trazem benefícios para as empresas de vestuário, com a otimização dos processos, a velocidade de produção e a conexão entre as máquinas, que permite a integração de toda a cadeia de valor. O presente artigo aborda a utilização de ferramentas da indústria 4.0 na prototipagem de produtos de vestuário. Aplicou-se a pesquisa básica com fundamentos teóricos, com uma abordagem qualitativa e descritiva. A coleta de dados foi realizada em livros, artigos científicos, teses e dissertações, trazendo os princípios e pilares da indústria 4.0, bem como as ferramentas que possibilitam a prototipagem 3D (tridimensional) de produtos de vestuário. Destaca-se a relevância da pesquisa tendo em vista que a análise global da viabilidade técnica do produto, que avalia o traçado da modelagem, a vestibilidade, os aspectos ergonômicos e o caimento das peças, são feitos em ambiente virtual, dispensando assim: a plotagem dos moldes, seleção e preparação do tecido para o corte, traçado do risco e corte dos moldes e montagem (preparação e costura) das peças do modelo de vestuário. Os resultados da pesquisa revelam que é possível ter eficácia na produção e na redução do tempo de trabalho e benefícios sustentáveis com o uso das ferramentas de prototipagem 3D para produtos de vestuário, em termos sociais, ambientais e financeiros.

Palavras-chave: Vestuário - Indústria; Prototipagem rápida; Modelagem tridimensional; Indústria 4.0. 


\begin{abstract}
The digital technologies of Industry 4.0, bring benefits to the clothing companies, with the optimization of the processes, the speed of production and the connection between the machines, which allows the integration of the entire value chain. This article discusses the use of tools from industry 4.0 in the prototyping of clothing products. Basic research with theoretical foundations was applied, with a qualitative and descriptive approach. Data collection was carried out in books, scientific articles, theses and dissertations, bringing the principles and pillars of industry 4.0, as well as the tools that enable 3D (threedimensional) prototyping of clothing products. The relevance of the research is highlighted, considering that the global analysis of the technical feasibility of the product, which assesses the layout of the modeling, the dressability, the ergonomic aspects and the trim of the pieces, are done in a virtual environment, thus dispensing: the plotting of the molds, selection and preparation of the fabric for cutting, tracing of the scratch and cutting of the molds and assembly (preparation and sewing) of the garment model pieces. The research results reveal that it is possible to be effective in the production and reduction of working time and sustainable benefits with the use of 3D prototyping tools for clothing products, in social, environmental and financial terms.
\end{abstract}

Keywords: Clothing and dress - Industry; Rapid prototyping; Three-dimensional modeling; Industry 4.0

Recebido em: 06/04/2021

Aceito em: 14/07/2021

\title{
1 INTRODUÇÃO
}

No cenário da sociedade contemporânea, as indústrias de vestuário procuram atender a demanda do novo modo de consumo e desafios que foram impostos à economia globalizada. No início do século XXI, o desenvolvimento das comunicações e mídias sociais e a facilidade de crédito, acarretaram em uma sociedade hedonista, viciada no prazer de consumir. Em relação a produtos de moda essa fase de consumo foi marcada pela consolidação do fast fashion, termo utilizado para definir a aceleração no consumo e produção de moda, as marcas que oferecem esse modelo de produto recebem novidades semanalmente, tornando esses produtos efêmeros.

Como consequência, ocorreram mudanças significativas na forma de produzir e vender os produtos de moda, tendo em vista novos modelos de negócios e abarcando além disso as vendas online. Esse tipo de comércio ganhou força com a pandemia de um novo vírus, identificado pela Organização Mundial da Saúde (OMS) como COVID-19. Diante desta situação mundial, no Brasil foram tomadas medidas pelos poderes públicos em níveis nacional, estadual e municipal para a contenção da pandemia com o fechamento de estabelecimentos das atividades não essenciais, com o isolamento social, entre outros protocolos de segurança (FOLHA, 2020). 
Nesse contexto, para atender as demandas de um consumidor ainda mais conectado em rede via internet, as indústrias de vestuário, buscaram por novas tecnologias digitais e de automação, bem como, sistemas de informações a serem usados nas etapas de planejamento, desenvolvimento e sistemas de produção. Cita-se como exemplo, os recursos tecnológicos e os softwares que estão disponíveis nos setores de criação, modelagem e corte, que impactam na redução do tempo de trabalho, no cronograma de execução do projeto e na diminuição dos custos de produção.

As indústrias de vestuário que investem, principalmente, em tecnologias informatizadas, tendem a atender as demandas de consumo de forma rápida e competitiva com preços atraentes, respeitando o meio ambiente e a sociedade, mantendo-se sustentável, também financeiramente. Diante deste cenário, determinou-se como problema de pesquisa o seguinte questionamento: Como a utilização de ferramentas da indústria 4.0 podem otimizar a prototipagem de produtos de vestuário?

Cabe mencionar, que o planejamento e controle da produção, em algumas empresas, ainda não está totalmente informatizado, o que implica em uma linha de produção com um custo e tempo de entrega maior que a demanda de mercado, indica a necessidade de integração entre os setores da indústria de vestuário, com sistema autônomo de produção e ferramentas digitais da Tecnologias de Informação e Comunicação (TIC). O que vai de encontro com Spricigo (2018), quando diz que os fundamentos básicos da Indústria 4.0, conectam os processos industriais com as máquinas de base digital com sistemas, que têm a capacidade e autonomia para agendar manutenções, prever falhas em processos e se adaptar a mudanças inesperadas que ocorrem nas etapas de produção.

Nesse ambiente industrial, as diferentes tecnologias, se integram a geração de soluções de acordo com as necessidades de cada setor da empresa, existindo inúmeras possibilidades de combinações e uso das tecnologias digitais, que podem impactar em toda a cadeia produtiva, na qual se insere a indústria de vestuário. Com as ferramentas digitais, é possível receber demandas diferenciadas dos clientes, agilizar os fornecedores de tecidos e aviamentos, programar a produção da forma mais eficiente, dada a integração das tecnologias digitais com as máquinas, os equipamentos e sistemas de alimentação e de distribuição de produtos. Portanto, com a difusão das tecnologias da Indústria 4.0, os sistemas trabalham de forma integrada com as ferramentas 
digitais, acelerando o ritmo de grandes escalas de produção, da ampla diversidade de produtos, com a criação e o lançamento de várias coleções anuais. O objetivo do presente artigo é identificar as ferramentas da indústria 4.0 que podem otimizar a prototipagem de produtos de vestuário.

A justificativa da pesquisa gira em torno do anseio de conhecer a aplicação prática da indústria 4.0 nas empresas de vestuário, desencadeado por experiências pessoais e relatos de colegas da profissão, que revelam a dificuldade na indústria de confecção de vestuário em encontrar o equilíbrio entre atender a demanda de consumo e se manter sustentável. Outra questão, se refere aos avanços tecnológicos digitais que deram suporte ao aumento do comércio eletrônico, principalmente no ano de 2020, com as lojas físicas fechadas por conta da Covid-19, muitos consumidores recorreram às compras online. Acredita-se também, que o estudo é relevante para as indústrias, pois podem se beneficiar de ferramentas de automação e de gestão para diferenciação e inovação de produto, de acordo com a necessidade do mercado.

Em relação aos procedimentos metodológicos, quanto a sua classificação, trata-se de uma pesquisa básica, com uma abordagem qualitativa do problema e quanto ao objetivo, um ponto de vista descritivo. No procedimento técnico, a fundamentação teórica se dará por meio de livros, artigos científicos, teses e dissertações publicadas no contexto do tema apresentado, observando a estrutura da indústria do vestuário, o conceito de indústria 4.0, seus pilares e principais benefícios, e também as ferramentas existentes para a prototipagem de produto do vestuário, como se aborda a seguir.

\section{INDÚSTRIA 4.0}

Em 2011, na Alemanha surgiu o termo Indústria 4.0, a partir de um projeto em uma Feira, na cidade de Hannover, denominado platform industrie 4.0 (plataforma indústria 4.0), com a finalidade de desenvolver alta tecnologia para fazer com que os sistemas automatizados que controlam os equipamentos industriais se comuniquem para trocar informações e dados entre máquinas e pessoas, para otimizar o processo de produção (SACOMANO et al., 2018).

Discorrendo o contexto histórico a primeira revolução industrial aconteceu por volta do fim do século XVIII e da primeira metade do século XIX. Ocasionada principalmente pela criação das máquinas a vapor que deram início a produção mecânica e a construção de ferrovias. A segunda 
revolução iniciou no fim do século $X I X$, ingressando no século $X X$, e foi impulsionada pelo surgimento da eletricidade e a linha de montagem, que permitiu a produção em série de grande escala. A terceira revolução é comumente conhecida como revolução digital ou do computador, tendo seu início no século XX na década de 1960 e foi impulsionada por tecnologias advindas nos anos subsequentes, como o desenvolvimento dos semicondutores, da computação em mainframe (computador de grande porte) da computação pessoal e da internet (SCHWAB, 2016).

Ainda de acordo com Schwab (2016), os três motivos a seguir acarretaram a ocorrência de uma quarta e distinta revolução:

a) Velocidade: ao contrário das revoluções anteriores, está evolui de forma exponencial e não linear. Resultado das peculiaridades e da interconexão da realidade contemporânea; sem contar a reprodução evolutiva das tecnologias;

b) Amplitude e profundidade: tendo a revolução digital como base e combinando várias tecnologias, causando a ruptura de paradigmas sem precedentes da economia, dos negócios, da sociedade e dos indivíduos. Afetando não só o modo como fazemos as coisas, mas também "quem" somos; e

c) Impacto sistêmico: envolve a alteração de sistemas inteiros entre países e dentro deles, em organizações e em toda a sociedade.

A partir dessas menções, que assinalam o contexto histórico da indústria 4.0, é possível compreender como surgiu e quais as principais causas da quarta revolução. Para aprofundar o conceito de Indústria 4.0 e a entender o seu papel na indústria, no texto seguinte estão também ilustrados quais os seus princípios.

\subsection{PRINCÍPIOS DA INDÚSTRIA 4.0}

Para desenvolver e implementar uma Indústria 4.0, Almeida (2019) afirma ser necessário ter como base seis princípios, que vão promover uma produção inteligente:

a) Capacidade de operação em tempo real - consiste em capturar e processar os dados instantaneamente, possibilitando a tomada de decisão ágil;

b) Virtualização - trata-se da realização de simulações e da existência de cópias digitais das fábricas; 
c) Descentralização - utilização de sistemas ciberfísicos para a tomada de decisão em tempo real, sempre com base nas necessidades produtivas;

d) Orientação a serviços - faz o alinhamento entre o conceito de Internet of Services e arquitetura de softwares, orientados a serviços;

e) Modularidade - uso de módulos na produção que facilitam a alternância de tarefas entre as máquinas; e

f) Orientação por serviço - refere-se à conexão de humanos e máquinas para a realização de determinadas tarefas. Esses serviços podem ser, por exemplo, a movimentação de um determinado produto de uma localização a outra de forma automatizada, com robôs fazendo a coleta de produtos.

Diante da descrição desses princípios, que caracterizam o contexto tecnológico da indústria 4.0, pode-se compreender a possibilidade de processamento de dados e armazenamento e a facilidade de acesso e troca de informações e conhecimentos. Esclarece-se detalhadamente seus benefícios a seguir.

\subsection{BENEFÍCIOS DA INDÚSTRIA 4.0}

A indústria 4.0 trouxe benefícios que proporcionam um avanço tecnológico entre outros fatores. Spricigo (2018), indica os seguintes benefícios:

a) Redução de custos - É um dos principais benefícios da Indústria 4.0 para quem precisa reduzir o orçamento e melhorar a qualidade para obter resultados com a diminuição de custos. Com a automação dos processos industriais os gastos menores, tendo as próprias máquinas autonomia para programar suas manutenções;

b) Economia de energia - O uso das tecnologias da I.4.0, aumenta a eficiência da captação e geração de energia, possibilitando economizar com a diminuição do consumo de energia e com aumento da capacidade de produtividade.

c) Aumento da segurança - As máquinas estando conectadas em rede, a produção é toda monitorada por meio de sensores, o que dá maior segurança operacional no chão de fábrica. Sendo assim, é possível prever falhas que possam evitar a paralisação das linhas 
de produção. Outra questão que contribui para a segurança dos processos é a diminuição do fator humano em tarefas repetitivas e até mesmo nas inseguras.

d) Conservação ambiental - A sociedade em geral preocupa-se com questões relacionadas à sustentabilidade. As novas tecnologias da I.4.0 ajudam a otimizar o uso de recursos naturais e diminuir o impacto da sua atividade no meio ambiente. Nesse ambiente, as empresas também precisam mostrar-se preocupadas e mostrar esses valores em ações de sustentabilidade que contribuam na preservação do meio ambiente. Muitos consumidores procuram adquirir produtos sustentáveis.

e) Redução de erros - As máquinas operando por meio de sensores, reduz a intervenção humana na linha de produção, bem como diminui as tarefas repetitivas e os erros cometidos nas etapas de produção. A qualidade dos produtos e os testes dos protótipos são mais garantidos, porque as máquinas são calibradas para manter um determinado nível de acerto.

f) Fim do desperdício - Quando se reduz os erros, aumenta-se a segurança e consequentemente o desperdício é reduzido ou totalmente eliminado. Nesse caso, os resultados são positivos para a economia dos gastos da empresa, tendo como resultado o aumento da competitividade.

g) Transparência nos negócios - Uma das vantagens da Indústria 4.0 é o maior controle das informações geradas durante a produção. Isso gera transparência nos negócios, com dados precisos sobre insumos, recursos e nível de utilização da capacidade instalada. Ter o domínio dessas informações garante mais facilidade em atrair investimentos para o seu negócio

h) Aumento da qualidade de vida - Com uma fábrica inteligente e mais automatizada, os funcionários passam a ter melhor qualidade de vida e tornam-se mais produtivos. Além disso, de forma geral, um país com indústria mais qualificada e produtiva gera melhor distribuição de riquezas para a sociedade; e

i) Customização em escala sem precedentes - As tecnologias implementadas na Indústria 4.0 ajudam a customizar os produtos de uma forma que nunca foi feita, em uma escala que era impossível para a manutenção de um negócio. Com as fábricas mais eficientes, passa a ser viável personalizar a produção para os consumidores. 
Em vista dos argumentos apresentados pelo autor, percebe-se a relevância da implantação e utilização das ferramentas e tecnologias aplicadas à indústria 4.0 para solução de problemas e otimização industrial, destacada em seguida.

\subsection{TECNOLOGIAS APLICADA À INDÚSTRIA 4.0}

A Indústria 4.0 está integrada a diversas inovações tecnológicas nos campos de automação e tecnologia da informação para os setores produtivos, com recursos físicos e digitais, conectando máquinas e sistemas. Destaca-se as principais tecnologias chaves da indústria 4.0, tendo como base os autores: Gaia (2016), Ashton (2016) e relatório de Boston Consulting Group (RÜßMANN et al., 2015).

Gaia (2016), destaca como principais tecnologias chaves da indústria 4.0: manufatura aditiva, robôs autônomos, sistemas físicos cibernéticos (Cyber-Physical Systems - CPS), computação em nuvem, big data and analytics, realidade aumentada, integração horizontal e vertical de sistemas, cibersegurança, simulação, internet das coisas (Internet of Things - IoT).

De acordo com relatório apresentado pelo Boston Consulting Group (RÜßMANN et al., 2015) são dez as tecnologias aplicadas à Indústria 4.0:

1) Robôs Inteligentes - capazes de interagir com outras máquinas e com os seres humanos, atuando de maneira mais flexível e colaborativa;

2) Manufatura Aditiva e Híbrida - permitindo a produção através de impressoras 3D;

3) Simulação Virtual - esta etapa permite que os processos e produtos sejam testados e ensaiados durante a fase de concepção, reduzindo custos com falhas e o tempo de projeto;

4) Integração Horizontal e Vertical dos Sistemas - sistemas ERP, MES, SAP que integram toda a cadeia de valor produtiva, por meio da análise e tomada de decisão de dados;

5) Internet das Coisas - permite conectividade entre os diversos dispositivos flexibilizando o acesso e controle em todo o processo produtivo;

6) Big Data \& Analytics - sistemas inteligentes que identificam falhas nos processos, melhorando a qualidade da produção em tempo real, economizando energia e melhorando a eficiência na utilização de todos os recursos produtivos; 
7) Cloud Computing - acesso ao banco de dados e suporte de qualquer local do planeta, permitindo a integração de sistemas e plantas em locais distintos, mesmo que distantes fisicamente, da mesma forma o controle e o suporte podem ser efetuados de maneira global;

8) Segurança Cibernética, sistemas de comunicação cada vez mais seguros e evoluídos garantindo o "accountability" do processo de produção (Fazer Certo a Primeira Vez, todas as Vezes);

9) Realidade Aumentada, suporte que permite que o usuário atue dentro dos sistemas ciber-físicos (CPS) com uma visão e tutoria assertiva indicando passo a passo todas as instruções e comandos necessários para um reparo, ou uma nova parametrização do processo. Com a indústria 4.0 haverá um aumento de produtividade e redução de custos nos processos fabris, melhor utilização dos recursos e economia de energia, sendo, portanto, um sistema para auxiliar no desenvolvimento sustentável; e

10) Ética, Princípios universais, que se fundamentam em ações morais exclusivamente pela razão, definida como a área que se ocupa do estudo das normas morais nas sociedades humanas. Para a indústria 4.0 a ética é de fundamental importância na transparência dos negócios, na cultura entre as empresas e na formulação dos preços das consultorias.

Na visão de Ashton (2016), as tecnologias da Indústria 4.0 dividem-se em dois grandes grupos:

1) Tecnologias que favorecem o crescimento do negócio com o aumento das receitas. Os produtos e serviços são inovadores em termos de funcionalidade e design, atraindo e mantendo os clientes; e

2) As tecnologias que permitem aumentar a produtividade reduzindo o risco. Estando conectada com o mercado em tempo real. Os processos produtivos são digitais, tendo o suporte das Tecnologias de Informação, Tecnologias Operacionais, automatizando todas as operações até as de pós-venda.

As tecnologias abaixo apresentadas, de acordo com Ashton (2016), são as ferramentaschave da Indústria 4.0:

a) Internet das coisas (IOT) - Trata-se de uma infraestrutura de rede que interliga objetos físicos e virtuais na qual os objetos cotidianos têm conectividade com a rede, 
permitindo que seja recebido e enviado dados através dos mesmos, de forma independente e inteligente, no qual resulta na otimização de um recurso. No contexto da indústria 4.0, a internet das coisas é fundamental devido a possibilidade de conexão entre máquinas por meio de sensores e dispositivos eletrônicos, na qual, permite e facilita a centralização e automação do controle de produção, ajudando-a a tornar-se uma indústria inteligente;

b) Robôs Automatizados - Além das funções atuais, futuramente, serão capazes de interagir com outras máquinas e com os humanos, tornando-se mais flexíveis e cooperativos;

c) Manufatura Aditiva - Produção de peças, por meio de impressoras 3D, que moldam o produto por meio de adição de matéria-prima, sem o uso de moldes físicos;

d) Fábricas inteligentes - Funciona com máquinas inteligentes e equipadas com sensores, possuem equipes de produção qualificadas e produtos inteligentes. Os sistemas de produção são integrados em processos administrativos dentro da empresa e horizontalmente em redes de valor agregado;

e) Simulação - Permite aos operadores testarem e otimizar processos e produtos ainda na fase de concepção, diminuindo os custos e o tempo de criação;

f) Sistema Físico-Cibernético - É a integração entre computadores e processos físicos, os quais monitoram e controlam as informações em tempo real. Com a aplicação deste sistema, a indústria garante um grande potencial na sua cadeia de produção. Esse sistema otimiza a indústria por meio de controle e monitoramento entre todos os processos de produção para atender da melhor maneira possível as necessidades dos clientes;

g) Big data - Refere-se à grande quantidade de dados armazenados pela empresa, acessados em tempo real, sendo utilizados para gerenciamento de informações, coletas, cruzamentos de dados, pesquisas e análises para tomadas de decisões. As indústrias com base nos dados que considerarem relevantes podem processá-los com o intuito de transformá-los em informações, com a finalidade de utilizar estas informações na criação de conhecimentos, usados nas tomadas de decisões inteligentes para agregar valor aos produtos e aos processos industriais; 
h) Nuvem - Banco de dados criado pelo usuário, capaz de ser acessado de qualquer lugar do mundo, por meio de uma infinidade de dispositivos conectados à internet;

i) Segurança Cibernética - A interligação de dados e informações entre todos os departamentos da cadeia produtiva da indústria exige muita cautela e segurança, sendo esta uma das principais preocupações e desafios na manufatura da indústria 4.0. Todas as tomadas de decisões devem levar em conta a segurança dos dados armazenados, o controle dos equipamentos e a eficácia dos sistemas de informações utilizados, garantindo o objetivo de uma automação independente, inteligente, eficiente e customizáveis; e

j) Realidade Aumentada - Sistemas baseados nesta tecnologia executam uma variedade de serviços, como selecionar peças em um armazém e enviar instruções de reparação por meio de dispositivos móveis.

A partir das tecnologias explanadas pelos autores citados, composto por princípios e benefícios, nota-se que é possível utilizar-se dessas ferramentas para promover novos avanços e rupturas para o setor de vestuário. No próximo tópico apresenta-se o contexto industrial de produção de vestuário.

Pode-se evidenciar algumas ferramentas já existentes que podem promover tais avanços, com ênfase nas ferramentas para a prototipagem de produtos de vestuário. Inclusive, mostrando imagens e explicando-as ou integrando-as no texto escrito.

\section{A INDÚSTRIA DO VESTUÁRIO}

Entre os anos de 1900 e 1925 aconteceu uma grande transformação na indústria de confecção: a confecção feita à mão passou gradativamente para a confecção industrializada, precursora do modelo de empresa do tempo presente. Já no século XX, a engenharia industrial começou a influenciar os métodos e os processos da indústria de confecção. E assim, as fábricas começaram a adotar métodos científicos para solucionar problemas de planejamento e produção, cronogramas e controles (LIDÓRIO, 2008). 
Na indústria do vestuário contemporânea, a tecnologia da confecção pode ser dividida pelas etapas de planejamento, desenvolvimento e produção. O Quadro 1 apresenta a classificação das etapas do processo de confecção de vestuário:

\section{Quadro 1 - Etapas processo de confecção de vestuário}

\begin{tabular}{|c|c|c|}
\hline \multicolumn{2}{|c|}{ ETAPAS } & AÇÕES \\
\hline \multirow{11}{*}{ PLANEJAMENTO } & \multirow{6}{*}{ Pesquisas } & Pesquisa de comportamento do público-alvo \\
\hline & & Pesquisa de mercado \\
\hline & & Pesquisa tecnológica \\
\hline & & Pesquisa de tendências de consumo \\
\hline & & Pesquisa sobre o tema da coleção \\
\hline & & Pesquisa das vendas de coleções anteriores \\
\hline & \multirow[t]{5}{*}{ Reuniões } & $\begin{array}{l}\text { Definição das características do produto e perfil } \\
\text { do consumidor }\end{array}$ \\
\hline & & Definição do cronograma \\
\hline & & $\begin{array}{l}\text { Definição dos parâmetros e dimensão da } \\
\text { coleção }\end{array}$ \\
\hline & & Estratégias de produção e de comercialização \\
\hline & & Definição do tema da coleção \\
\hline \multirow{17}{*}{ DESENVOLVIMENTO } & \multirow{8}{*}{ Criação } & Tema de coleções - Painéis; tendências \\
\hline & & Inspiração do tema \\
\hline & & Público-alvo \\
\hline & & Cartela de cores \\
\hline & & Amostra de tecidos e aviamentos \\
\hline & & $\begin{array}{l}\text { Geração de alternativas } \\
\text { triagem/seleção }\end{array}$ \\
\hline & & Definição de tamanho \\
\hline & & Desenho técnico/Ficha técnica \\
\hline & \multirow{5}{*}{ Modelagem } & Traçado Básico do corpo humano \\
\hline & & Interpretação do desenho técnico \\
\hline & & Traçado da Modelagem \\
\hline & & Moldes \\
\hline & & Graduação (após aprovação do protótipo) \\
\hline & \multirow{4}{*}{ Prototipagem } & Confecção do protótipo \\
\hline & & Análise do protótipo \\
\hline & & Aprovação do protótipo \\
\hline & & Peça piloto \\
\hline \multirow{7}{*}{$\begin{array}{l}\text { PLANEJAMENTO E CONTROLE DA } \\
\text { PRODUÇÃO }\end{array}$} & \multirow{3}{*}{$\begin{array}{l}\text { Planejamento do } \\
\text { risco e do corte }\end{array}$} & Programação das peças para o risco e corte \\
\hline & & Estudo do encaixe \\
\hline & & Enfesto/Corte \\
\hline & \multirow{4}{*}{$\begin{array}{l}\text { Controle da } \\
\text { Confecção }\end{array}$} & Mostruário \\
\hline & & Lotes das peças para costura \\
\hline & & Controle da qualidade \\
\hline & & Embalagem \\
\hline
\end{tabular}

Fonte: Adaptado de Montemezzo (2003), Treptow (2013) e Silveira; Puls (2017). 
As etapas exibidas no Quadro 1, mostram um panorama geral da indústria de vestuário, em relação às etapas do processo de confecção de vestuário. Essas etapas podem ter alterações na sequência ou em nomenclaturas de acordo com a empresa, e o seu segmento. Ressalta-se que esses processos foram se moldando de acordo com a evolução da indústria, e contam com diversas ferramentas já existentes que auxiliam na conclusão de cada uma das etapas.

A Indústria de vestuário, assim como os demais setores, também passou por transformações durante as revoluções industriais. Segundo Vasques; Pelegrini (2011, p. 2) "adventos tecnológicos, a industrialização e aumento do comércio, o mercado têxtil ganhou espaço considerável e, à medida que a produção e o consumo foram crescendo, a modernização da mecanização das operações foi acelerando". A modernização no processo de confeç̧ão aconteceu em vários segmentos desde a produção do tecido até a confecção do produto.

Como o objetivo da pesquisa é identificar a utilização das ferramentas da indústria 4.0 na prototipagem de produtos de vestuário, descreve-se esse processo.

\subsection{PROTOTIPAGEM DE PRODUTOS DE VESTUÁRIO}

De acordo com o Quadro 1, no âmbito do convencional, a prototipagem é iniciada pela confecção do protótipo que na grande maioria das vezes é feito com tecido similar, não é utilizado o tecido final para otimizar os custos nessa etapa, devido às alterações que podem ocorrer. Com o protótipo confeccionado acontece a verificação de caimento e vestibilidade e sempre que tiver alguma alteração, o molde deve ser atualizado e reinicia-se o processo de prototipagem até se alcançar o pretendido (SILVEIRA, 2011).

$\mathrm{Na}$ indústria do vestuário, a prototipagem pode apontar diversas inconformidades. São realizados testes técnicos e ergonômicos para verificar a eficiência técnica, a qualidade e a interação com o usuário, estes são primordiais para antecipar situações de uso e aceitação no mercado, prevendo a incidência de eventuais correções (MONTEMEZZO, 2003). Esses testes são feitos geralmente em uma pessoa com as medidas padrões da tabela adotada pela empresa ou em manequins. O protótipo é avaliado e conforme os resultados é definido se a peça está aprovada ou se ainda são necessários ajustes (PIRES, 2015). 
A peça piloto é confeccionada quando o protótipo é aprovado sem restrições, como também os moldes são encaminhados para setor de modelagem, onde serão graduados (ampliação e redução para os demais tamanhos). Finalmente, a peça piloto é encaminhada para o setor de confecção como modelo padrão para orientar a produção, por esse motivo deve contemplar todos os aspectos do produto final (SILVEIRA, 2011). Com o advento da 1.4 .0 alguns processos manuais usados na prototipagem são substituídos por ferramentas digitais, como descreve-se a seguir.

\subsection{FERRAMENTAS DA INDÚSTRIA 4.0 PARA A PROTOTIPAGEM DE PRODUTOS DE VESTUÁRIO}

$\mathrm{Na}$ indústria de vestuário, as etapas de criação e prototipagem, podem ser consideradas fundamentais para definir os padrões que devem ser seguidos na produção em escala. É recorrente as empresas usarem ferramentas da indústria 4.0 para o planejamento e criação de coleção, modelagem, graduação, risco e no corte do tecido, porém o protótipo ainda é desenvolvido em sua forma física em um processo manual, com a necessidade da matéria-prima e todo o maquinário usado para a produção em massa, incluindo o tempo gasto e mão de obra.

Contudo é possível encontrar uma grande variedade de empresas que desenvolvem e oferecem sistemas de prototipagem 3D para a indústria do vestuário, como por exemplo: Accumark V-Sticher da Gerber, com a parceria da empresa Browzwear, especialista em 3D para indústria da Moda (PIRES, 2015). A Figura 1 mostra alguns exemplos. Runwawy da Optitex, Modaris fit 3D oferecido pela Lectra, software Vidya criado pela Assist Bullmer, o Audaces 3D e o Clo 3D, desenvolvido pela Clo Virtual Fashion, responsável também pelo desenvolvimento de outros softwares 3D para o setor de computação gráfica (PIRES, 2015).

Figura 1- Interface dos softwares de prototipagem 3D

Accumark V-Sticher 3D Runwawy




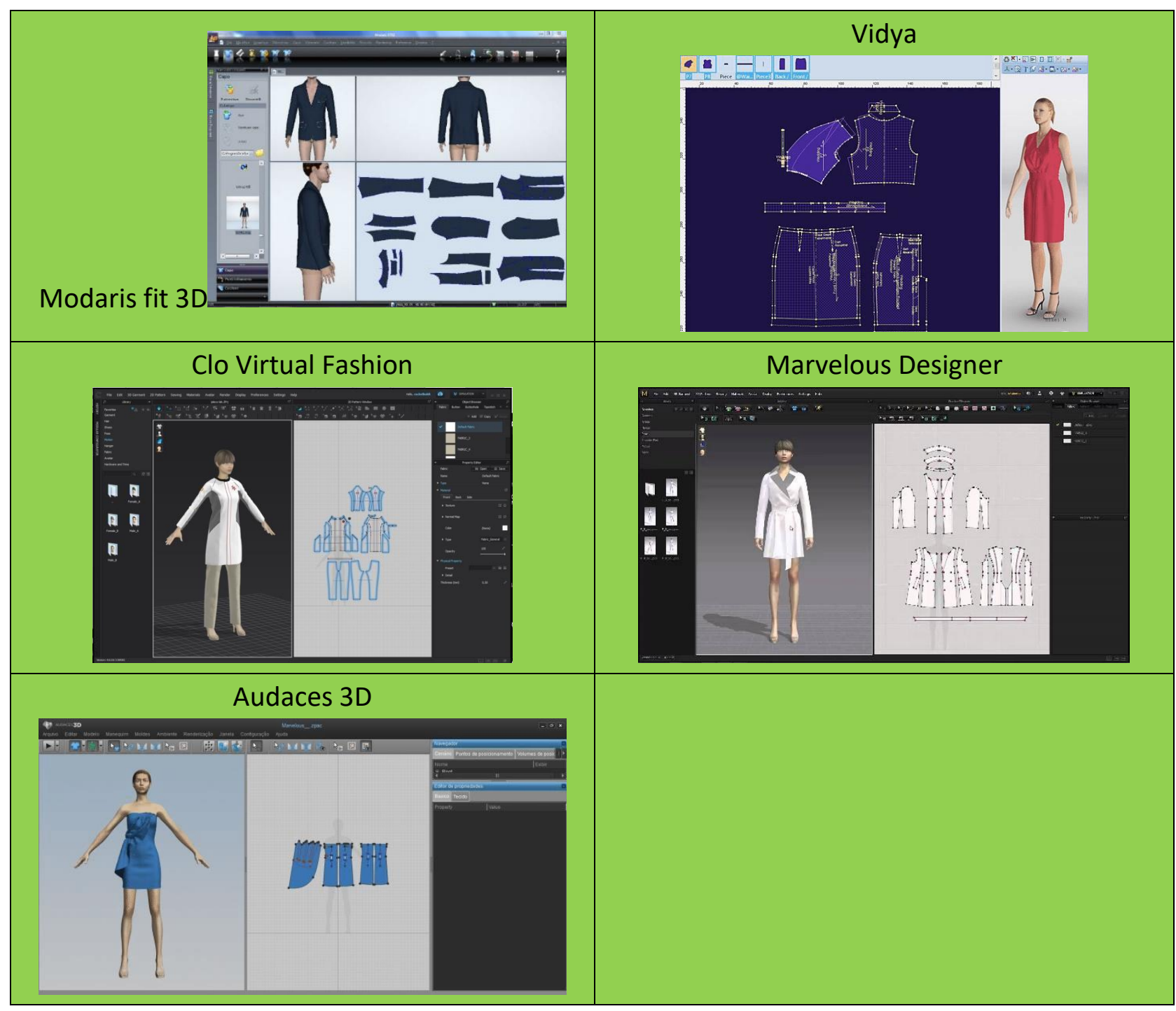

Fonte: Adaptado de Pires (2015).

É possível observar na Figura 1, que as interfaces dos softwares são muito similares, elas são compostas por uma a janela onde fica o manequim virtual e outra janela onde aparece a modelagem bidimensional e as caixas de ferramentas.

Como esclarece Pires (2015), esses softwares de prototipagem 3D, possuem manequins virtuais que simulam o corpo humano, e suas medidas podem ser configuradas de acordo com a necessidade do usuário. O manequim virtual pode ser do gênero masculino ou feminino, adulto ou infantil, cujas medidas das dimensões corpóreas podem ser de alteradas de acordo com o perfil de consumidor que a empresa deseja atingir. 
A partir da preparação dos manequins virtuais, inicia-se o processo de desenvolvimento da modelagem e simulação das costuras de cada parte do molde desenvolvido.

É fundamental para a prototipagem 3D a construção prévia de uma modelagem plana, que pode ser feita de forma informatizada, utilizando softwares das mesmas empresas citadas ou de forma manual para serem digitalizadas na sequência. É necessário também conhecimento de construção de peça (costura) para ativar os comandos corretos da prototipagem 3D. Os pontos de costura são identificados para a montagem da peça como podem ser observados na Figura 2 e 3.

Figura 2 - Aplicação das costuras no protótipo (Audaces 3D)

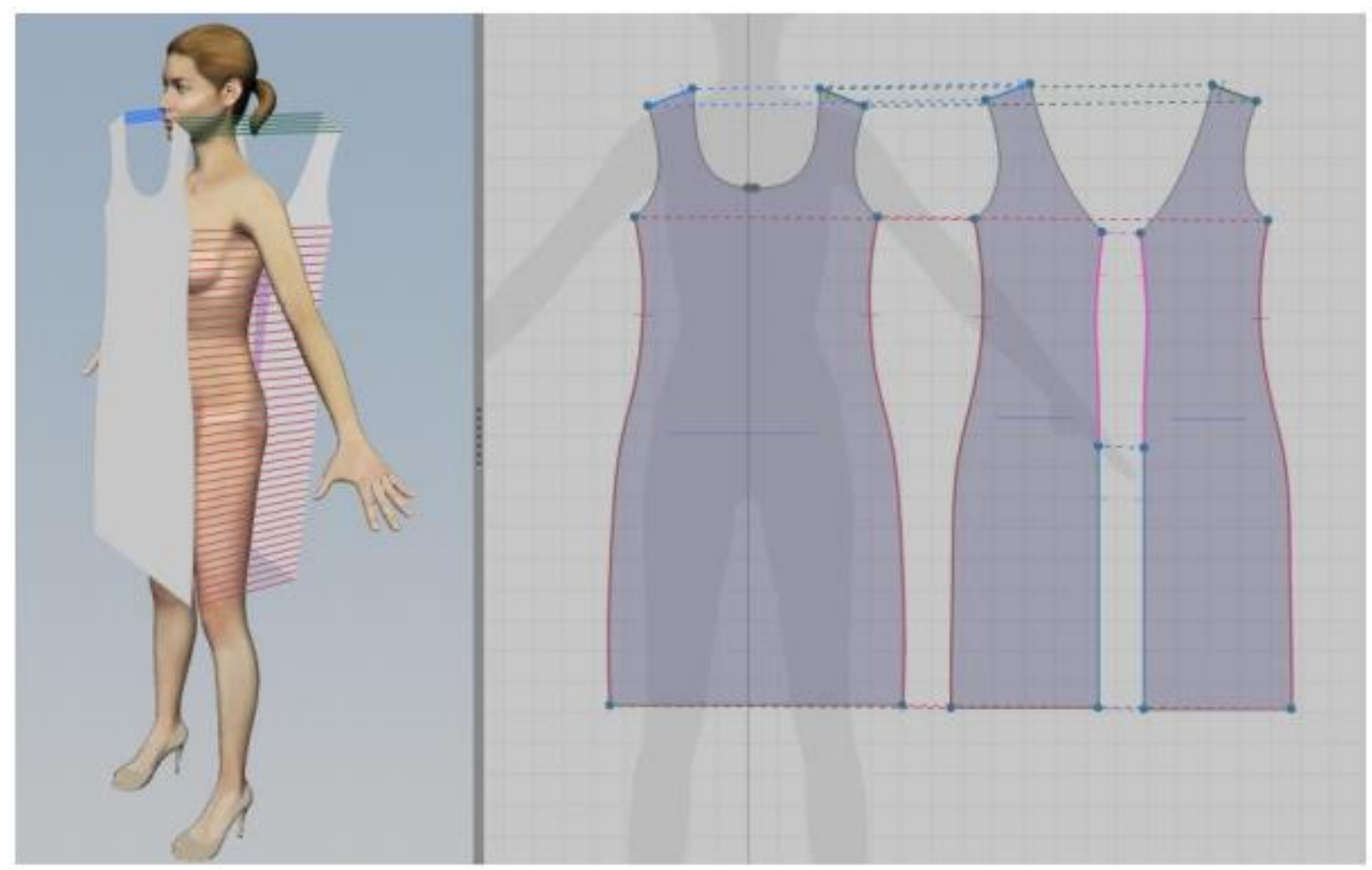

Fonte: Pires (2015).

Na Figura 2 é possível ver de forma ampliada as janelas do manequim e da modelagem bidimensional e como são aplicadas as costuras das partes, evidenciando como os conhecimentos técnicos, dos profissionais que atuam na prototipagem física dos produtos de vestuário são indispensáveis mesmo na virtualização da prototipagem. Completa-se a observação da colocação das costuras na Figura 3. 
Figura 3 - Costuras aplicadas no software Audaces 3D para simulação

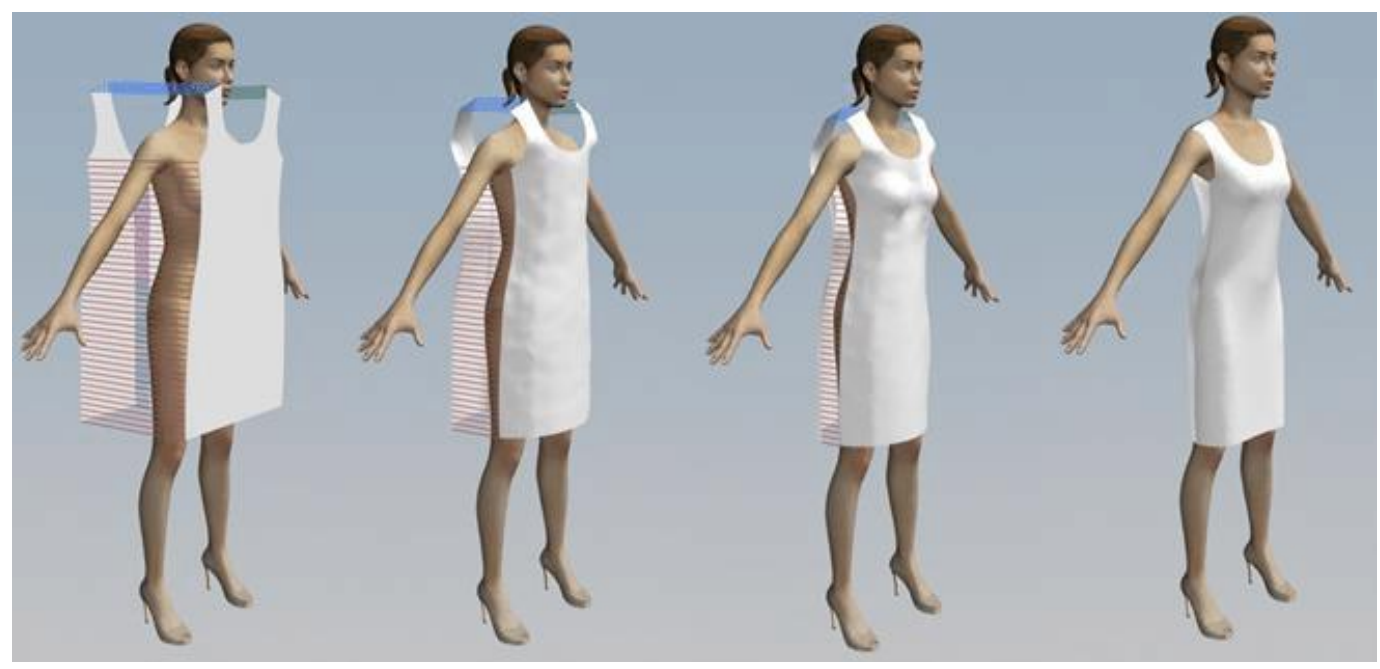

Fonte: https://www.researchgate.net/figure/Figura-14-Costuras-aplicadas-no-software-Audaces3D-para-simulacao-Para-o-alcance-de_fig14_313593099

Com as costuras inseridas é realizada a simulação da união dos moldes, sendo possível visualizar a transição que faz com que as peças sejam "costuradas", moldando o corpo do manequim virtual. Como pode ser observado na Figura 3, a simulação inclui o tecido do modelo do vestuário. Os designers, modelista e demais profissionais do setor de vestuário, precisam conhecer os tipos de tecidos, para selecionar os que mais se adequam ao modelo. Silveira (2011), explica que quando um tecido não é adequado ao modelo do vestuário, a peça pode não ficar com o caimento desejado e o resultado acaba sendo completamente diferente do que se esperava. Assim, é preciso conhecer as características dos tecidos e observar os detalhes do estilo do modelo, o caimento no corpo e a ocasião em que vai ser utilizado.

Sobre o caimento, Chataignier (2006) explica que é a queda proporcionada pelo grau de flexibilidade, maleabilidade ou consistência do tecido. Portanto, o aspecto visual de qualquer peça de vestuário está relacionado com as características técnicas dos tecidos e também sobre a forma com que os moldes são posicionados no momento do corte do tecido.

Portanto, para o desenvolvimento de protótipos de vestuário nos softwares CAD 3D, é necessário inserir no sistema as informações referentes ao tecido. Tendo em vista que a construção do tecido influência diretamente na concepção do protótipo 
Os softwares de modelagem virtual 3D também favorecem a prototipagem de produtos de vestuário, com ferramentas que proporcionam a visualização e o teste das cores e estampas no protótipo virtual, pois permitem a simulação do modelo com diferentes cores, padronagens e estampas. Diante do exposto, a análise de modelos de vestuário em protótipos virtuais, diminuem as etapas de trabalho executadas com protótipos físicos, pois além da diminuição do tempo e custos, permite a visualização do modelo, das cores, estampas e caimento facilitando as correções necessárias antes da confecção da peça piloto, como destacado na análise dos resultados.

\section{ANÁLISE DE RESULTADOS DA PESQUISA}

A simulação 3D na produção industrial de vestuário antecipa as etapas de corte e costura, prova de peça teste, ajustes na modelagem, corte da peça piloto (protótipo), estampa/bordado peça piloto (protótipo), costura da peça piloto (protótipo), simplificando e compactando todas as etapas em uma única ferramenta (Quadro 2).

Quadro 2 - comparação de processos de prototipagem Física e 3D

\begin{tabular}{|c|c|}
\hline Protótipo Físico & Protótipo 3D \\
\hline $\begin{array}{l}\text { Desenvolvimento de modelagem no } \\
\text { sistema } C A D \quad(2 D) \text { ou digitalização de } \\
\text { modelagem realizada em processo manual }\end{array}$ & $\begin{array}{l}\text { Desenvolvimento de modelagem no } \\
\text { sistema } C A D \quad \text { (2D) ou digitalização de } \\
\text { modelagem realizada em processo manual }\end{array}$ \\
\hline Encaixe automatizado - CAD (2D) & \multirow{5}{*}{$\begin{array}{l}\text { SIMULAÇÃO DE PROTOTIPAGEM EM 3D - } \\
\text { realizada em sistema computadorizado }\end{array}$} \\
\hline Plotagem dos moldes & \\
\hline Definição do tecido & \\
\hline Corte & \\
\hline Costura & \\
\hline
\end{tabular}

Fonte: adaptado Pires (2015).

A utilização da ferramenta de simulação apontada pelos autores Gaia (2016), Ashton (2016) e relatório de Boston Consulting Group (RÜßMANN et al., 2015) como pilar da indústria 4.0, pode otimizar a prototipagem de produtos de vestuário. Oferecendo os seguintes benefícios da indústria 4.0 apontados também pelo autor Spricigo (2018): 
a) Redução de custos - Com a simulação 3D dos protótipos de produtos do vestuário, pode acontecer uma redução de custo, considerando a economia de tempo (plotagem dos moldes, seleção e preparação do tecido para o corte, traçado do risco e corte dos moldes, costura das peças do modelo de vestuário). Toda a análise global da modelagem, vestibilidade, aspectos ergonômicos e caimentos das peças serão feitos no ambiente virtual;

b) Economia de energia - A redução na quantidade de peças testes produzidos, diminui o consumo de energia com as máquinas de costura e corte;

c) Aumento da segurança - As operações de corte e costura de peças teste no setor de vestuário, tem um grande de risco de acidentes, logo a diminuição da produção das mesmas diminui esse risco, e

d) Conservação ambiental e fim do desperdício - A produção de peças testes gera um número considerável de resíduos têxteis (no corte e quando não são aprovadas), visto que nem todas as peças são aprovadas na primeira prototipagem e nem finalizadas, acabando muitas vezes se tornando resíduo.

Diante do exposto, constatou-se que utilizar softwares 3D para uma pré-aprovação de protótipos é uma forma eficaz de analisar a modelagem, a estrutura do modelo sobre o corpo, o caimento e volume do tecido, bem como a sua forma estética, com diferentes cores, tecidos e padronagens. Contudo, é importante ressaltar que essa eficácia é possível apenas, quando os profissionais responsáveis no desenvolvimento do protótipo virtual, tenham amplo conhecimentos das ferramentas do software, de modo que possam manuseá-la de forma adequada, na representação dos tecidos, modelagem e costura.

Spricigo (2018), coloca que as indústrias de vestuário contam com o software "Made to Measure" (Gerber's AccuMark ${ }^{\circledR}$ ), embora existam outros, que fazem o escaneamento do corpo em 3D, podendo ser ajustada as medidas dos protótipos, enquanto os movimentos são simulados (Figura 4). 
Figura 4 - Obtenção das medidas do corpo com a simulação de movimentos

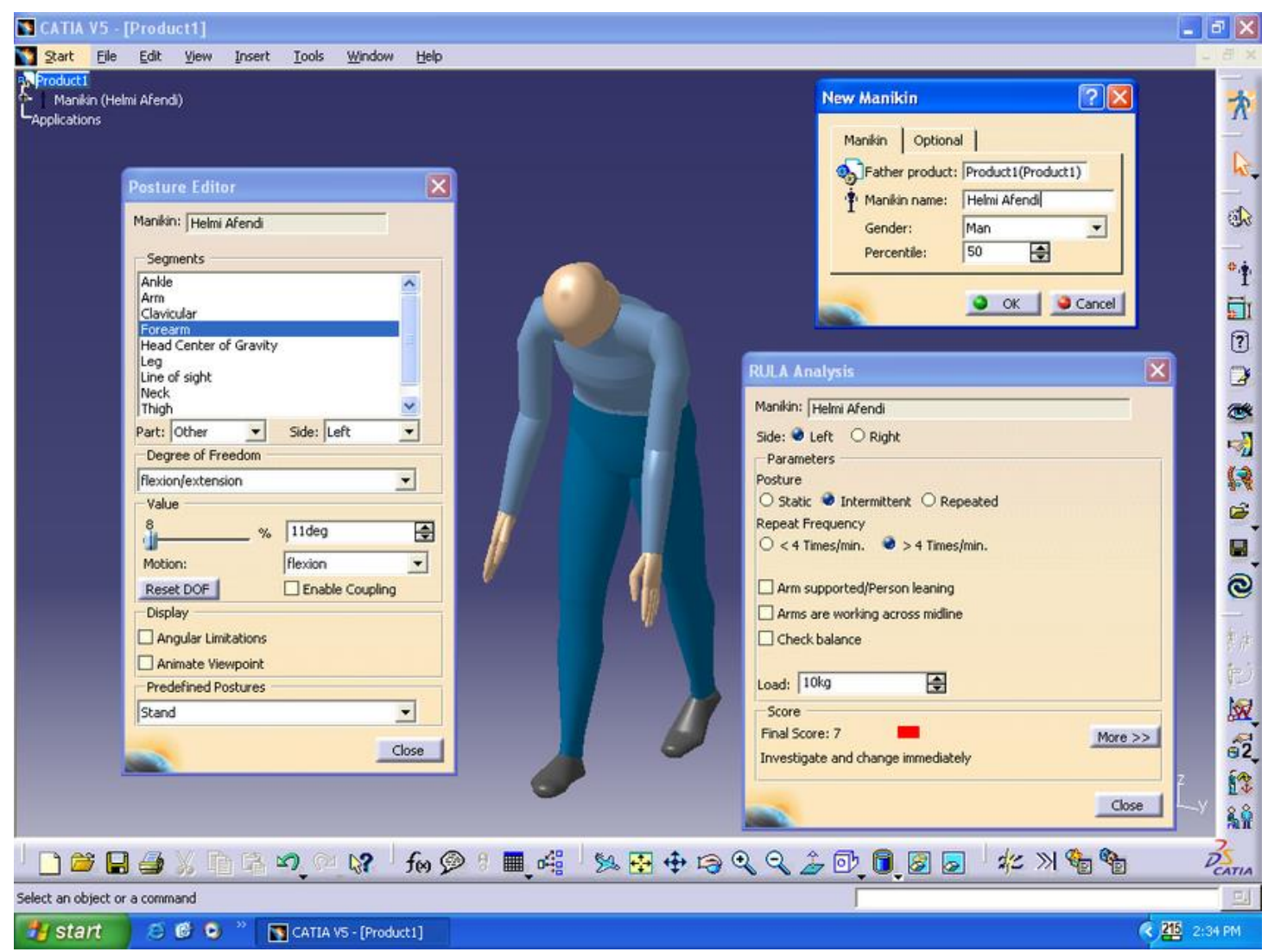

Fonte:https://www.researchgate.net/figure/The-simulation-of-RULA-analysis-using-CATIA-software_fig1_282273079.

O body scanner faz a obtenção de medidas do corpo de forma rápida e precisa, e isso pode contribuir para gerar a possibilidade realizar a prototipagem de peças de vestuário de acordo com a silhueta de cada usuário.

O processo de modelagem requer vários testes de prototipagem para a adequação das medidas do modelo ao corpo do público-alvo e do tecido ao caimento requerido para o modelo, até chegar ao molde desejado, tendo em vista a vestibilidade do produto. Este processo pode ser acelerado com este tipo de soluções 3D. Destaca-se como exemplo na Figura 5, a comparação de caimento de tecidos e vestibilidade de acordo com o processo manual e virtual do protótipo. 
Figura 5: Comparação de caimento de tecidos e vestibilidade
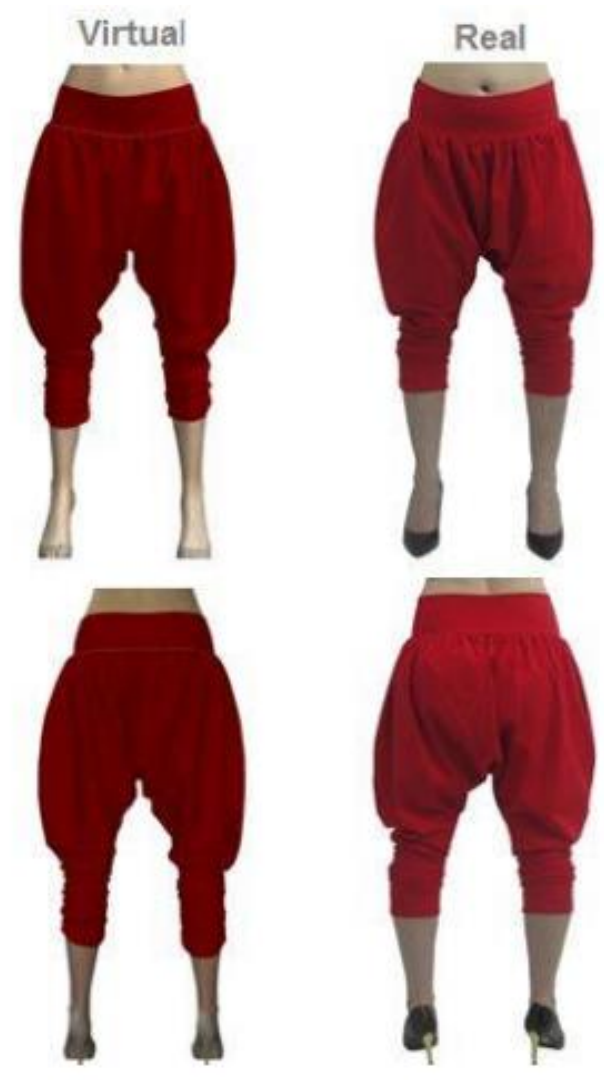

\section{Modelo 1 Material: cotton}
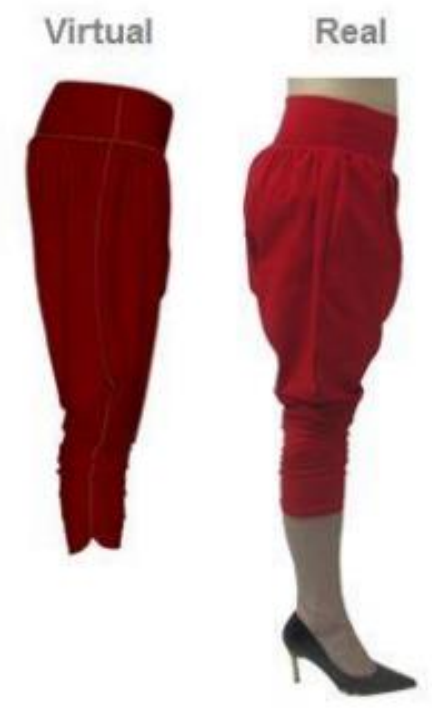

Fonte: Pires (2015).

Na figura 5 é possível observar a similaridade entre a prototipagem física e 3D, o que comprova juntamente com os dados anteriores a viabilidade e eficácia da utilização da prototipagem 3D no setor de vestuário.

O alto nível de fidelidade da simulação 3D é um grande avanço também, na possibilidade de compras pela internet. Essa integração entre o design de roupas e a modelagem, resultam em um produto 3D interativo, que pode facilitar a virtualização do desenvolvimento de produtos e do marketing (BRUNO, 2016).

A utilização dos softwares como Computer Aided Design (CAD) ou Computer Aided Manufacturing (CAM) - (Desenho Assistido por Computador e Manufatura Assistida por Computador) são usados para projetar e fabricar protótipos, sendo capazes de interagir com sistemas inteligentes de prototipagem em tempo real, permitindo a integração da impressão 3D com recurso de sistemas ciber-físicos e Realidade Aumentada. 
A modelagem das peças de vestuário, são arquivadas no sistema $C A D$ e facilmente integrada a base de dados de tecidos, podendo assim, ser realizado testes de protótipos 3D com diferentes tipos de tecidos. A prototipagem em 3D e as tecnologias da comunicação podem também reduzir as despesas de viagem e o número de protótipos e amostras utilizados no processo, enquanto se minimiza desperdícios de tecido e se poupa tempo.

A ferramenta da Realidade Aumentada pode ser utilizada para criar modelos de protótipos virtuais, ajudando os utilizadores a avaliar melhor os seus desenhos e a modificá-los adequadamente (TORI, 2009). Na indústria de vestuário o aspeto estético tem um grande peso na tomada de decisão dos consumidores quando adquirem uma peça. Além dos aspectos estéticos, os modelos de vestuário devem vestir bem o corpo do público-alvo. Como existe uma grande variedade de pessoas com diferentes características físicas, é um grande desafio desenvolver um produto que assente bem em vários tipos de corpos ou desenvolver várias variantes de um produto para os vários tipos de corpos. Neste caso, a Realidade Aumentada é uma boa solução para conseguir desenvolver peças virtuais tendo por base um corpo humano real. Amostras digitais podem acabar com a necessidade produzir mostruários, o que ajuda os designers, os fabricantes e os representantes comerciais.

As inovações desenvolvidas para o setor têxtil e vestuário a integradas na cadeia de valor deste setor, podem aumentar a produtividade, dando mais rapidez no processo até chegar ao cliente, redução de custos e diminuição de desperdícios. Deste modo é possível concluir que a iniciativa Indústria 4.0 poderá ser benéfica para a produção de vestuário em todas as fases da cadeia de valor com os desafios impostos pelo mercado de moda, que requerem modelos cada vez mais inovadores e diferenciados.

\section{CONCLUSÃO}

Por meio da observação dos dados apresentados no presente artigo é possível constatar que o objetivo proposto foi alcançado. As ferramentas de simulação 3D existentes para a prototipagem na indústria do vestuário se mostram altamente eficazes, e destaca-se a importância da consolidação do seu uso para a prototipagem, de forma a otimizar a fabricação de produtos de vestuário, tendo em vista os inúmeros benefícios relatados na pesquisa. 
O uso de ferramentas da indústria 4.0 para solução de problemas recorrentes do setor de vestuário, pode ser considerada fundamental, diante dos atuais paradigmas encontrados no segmento como por exemplo a necessidade de aceleração e customização na entrega dos produtos, além da conscientização quanto a exploração de recursos e o descarte de resíduos, que na realidade contemporânea podem ser favorecidos com soluções da indústria 4.0.

Destaca-se ainda, que a implantação da Indústria 4.0 será alavancada pelos robôs, sensores e tecnologia da informação e comunicação. Porém, mesmo com a indicação de ganhos de produtividade e qualidade, essa profusão tecnológica tende a exigir dos profissionais do setor industrial de vestuário, qualidades como talento e raciocínio, e não apenas conhecimentos técnicos, que podem fazer diferença no desempenho de funções.

Esta pesquisa, pode ainda ser aprofundada, dentro do eixo da utilização de ferramentas indústria 4.0 na indústria do vestuário, abordando o estudo das minis fábricas, de produtos personalizados, além da automatização da produção em série, aumentando assim, contribuição com novos conhecimentos para a sociedade e para a academia.

\section{REFERÊNCIAS}

ALMEIDA, P. S. de. Indústria 4.0: princípios básicos, aplicabilidade e implantação na área Industrial. Editora: Saraiva Educação, 2019.

ASHTON, K. A história secreta da criatividade. Rio de Janeiro: Sextante, 2016.

BRUNO, F. da S. A quarta revolução industrial do setor têxtil e de confecção: a visão de futuro para 2030. São Paulo : Estação das Letras e Cores, 2016. Disponível em: https://bibliotecas.sebrae.com.br/chronus/ARQUIVOS_CHRONUS/bds/bds.nsf/b4a04ab45a138e42 aec2a4762f18b5c8/\$File/7585.pdf. Acesso em: 24 nov. 2020.

CHATAIGNIER, G. Fio a fio: tecidos, moda e linguagem. São Paulo: Estação das Letras, 2006.

FOLHA informativa sobre COVID-19. In: OPAS/OMS . Brasília : Organização Pan-Americana da Saúde, [2020]. Disponível em:

https://www.paho.org/bra/index.php?option=com_content\&view=article\&id=6101:covid19\&ltemi d=875. Acesso em: 19 out. 2020.

GAIA, P. A quarta revolução industrial e as tendências tecnológicas no segmento de equipamentos, máquinas e acessórios industriais. O Papel: revista mensal de tecnologia em celulose e papel, [s. I.], 
v. 77, n. 5, p. 21-25, 2016. Disponível em: http://www.celuloseonline.com.br/47807-2/. Acesso em: 20 out. 2020.

LIDÓRIO, C. F. Tecnologia da confecção. Araranguá: Instituto Federal de Educação, Ciência e Tecnologia de Santa Catarina, 2008. Disponível em:

https://wiki.ifsc.edu.br/mediawiki/images/temp/5/52/20080729221515!Apostila_CTQ_edi\%C3\%A7 \%C3\%A3o_1.pdf. Acesso em: 20 nov. 2020.

MONTEMEZZO, M. C. de F. S. Diretrizes metodológicas para o projeto de produtos de moda no âmbito acadêmico. 2003. Dissertação (Mestrado em Desenho Industrial) - Universidade Estadual Paulista, Faculdade de Arquitetura, Artes e Comunicação, Bauru, 2003. Disponível em: https://repositorio.unesp.br/handle/11449/97020. Acesso em: 30 nov. 2020.

PIRES, G. A. O CAD 3D aplicado na validação de protótipos na indústria do vestuário. 2015. Dissertação (Mestrado em Design) - Universidade Estadual Paulista, Faculdade de Arquitetura, Artes e Comunicação, Bauru, 2015. Disponível em:

https://repositorio.unesp.br/bitstream/handle/11449/132882/pires_ga_me_bauru_int.pdf?sequen ce=3\&isAllowed=y. Acesso em: 27 nov. 2020.

RÜßMANN, M. et al. Industry 4.0: The future of productivity and growth in manufacturing industries. In: Boston Consulting Group, 9 Apr. 2015. Disponível em: https://www.bcg.com/ptbr/publications/2015/engineered_products_project_business_industry_4_future_productivity_gro wth_manufacturing_industries.Acesso em: 23 nov. 2020.

SACOMANO, J. B. et al. Indústria 4.0: conceitos e fundamentos. São Paulo: Blucher, 2018.

SCHWAB, K. A quarta revolução industrial. São Paulo: Edipro, 2016.

SILVEIRA, I.; PULS, L. M. Modelo de gestão do conhecimento: capacitação da modelagem de vestuário. Florianópolis: UDESC, 2017. (Teses de Moda; v. 2). Disponível em:

https://www.udesc.br/arquivos/ceart/id_cpmenu/3348/livro_teses_de_moda_icleia_silveira_1523 2959222134_3348.pdf. Acesso em: 23 nov. 2020.

SILVEIRA, I. Um modelo para capacitação dos instrutores do sistema CAD para vestuário e dos modelistas, com foco na gestão do conhecimento.2011. Tese (Doutorado em Design) - Pontifícia Universidade Católica, Rio de Janeiro, 2011. Disponível em:

https://repositorio.unesp.br/bitstream/handle/11449/132882/pires_ga_me_bauru_int.pdf?sequen ce=3\&isAllowed=y. Acesso em: 14 dez. 2020.

SPRICIGO, B. Resumo sobre Indústria 4.0: entenda rapidamente os conceitos e benefícios. In: Pollux. Joinville, 16 mar. 2018. Disponível em: https://www.pollux.com.br/blog/resumo-sobreindustria-4-0-entenda-rapidamente-os-conceitos-e-beneficios/. Acesso em: 23 nov. 2020. 
TORI, R. Desafios para o Design de Informação em Ambientes de Realidade Aumentada. InfoDesign - Revista Brasileira de Design da Informação, São Paulo, v. 6, n. 1, p.46 - 57, 2009. DOI: https://doi.org/10.51358/id.v6i1.70. Disponível em: https://www.infodesign.org.br/infodesign/article/view/70. Acesso em: 13 nov. 2020.

TREPTOW, D. Inventando moda: planejamento de coleção. 5. ed. Brusque: do Autor, 2013.

VASQUES, R. S. ; PELEGRINI, S. C. A. O produto têxtil: moda e história na década de 1960. In: COLÓQUIO DE MODA, 7., 2011, Maringá. Anais eletrônicos [...]. Maringá : Cesumar, 2011. Disponível em: https://www.coloquiomoda.com.br/anais/Coloquio\%20de\%20Moda\%20\%202011/GT08/ComunicacaoOral/CO_895930_Produto_Textil_Moda_e_Historia_na_Decada_de_1960.pdf. Acesso em: 20 nov. 2020. 